\title{
A Study of the Outcomes of 103 Pregnant Women Admitted with Malaria at Three District Hospitals in Mashonaland East Province and One Central Hospital in Harare Province in Zimbabwe
}

\author{
${ }^{1 *}$ Muchabayiwa F Gidiri, FRCOG, ${ }^{2}$ Reuben Bishi, MMed O\&G, \\ ${ }^{1}$ Thulani L Magwali, MMed O\&G \\ ${ }^{1}$ Academic Department of Obstetrics and Gynaecology, \\ B-Floor Old health Sciences Building \\ University of Zimbabwe College of Health Sciences, \\ Mazowe Street, Avondale, Harare, Zimbabwe \\ ${ }^{2}$ Mutare Provincial Hospital, \\ Department of Obstetrics and Gynaecology, \\ Mutare, Zimbabwe
}

*Corresponding Author:

\section{Dr Muchabayiwa F Gidiri}

University of Zimbabwe College of Health Sciences

Department of Obstetrics and Gynaecology

B-Floor Old Health Sciences Building,

Mazowe Street, Avondale, Harare, Zimbabwe

\begin{abstract}
Objectives: To evaluate maternal and fetal outcomes and factors that influence these outcomes in women diagnosed with malaria in pregnancy. Design: A cross-sectional descriptive study of women admitted with malaria over an 8-month period using an interviewer-administered questionnaire plus case notes review for prospective data collection. Setting: The study setting was three district hospitals in a high seasonal malarial province and a central hospital in a non-malarial urban area in Zimbabwe. Subjects: There were 103 women admitted with malaria at the four study centres during the study period. Results: Maternal outcomes assessed were maternal deaths 2(2\%), cerebral malaria 2(2\%) and severe anaemia 6(6\%). Maternal adverse outcomes appear to have been influenced by antenatal booking status, HIV infection, use of preventive measures and late presentation to hospital. Of the 51 patients delivered by the time of discharge, 23\% were live term births, $10 \%$ preterm births, $10 \%$ low birth weight babies, $6 \%$ stillbirths and $9 \%$ miscarriages. Nearly half the patients did not use intermittent preventive treatment. Conclusion: Malaria is a significant cause of maternal and perinatal morbidity and mortality. However, most women if diagnosed and treated early will recover and have a good pregnancy outcome. Women living in malaria endemic areas may benefit from intermittent preventive treatment (IPT) and early booking for antenatal care enables them to access IPT and insecticide treated bed nets (ITNs) where available.
\end{abstract}

\section{INTRODUCTION}

The majority of malaria cases in Zimbabwe are due to plasmodium falciparum.

Malaria is transmitted by the female anopheles mosquito, which is widely distributed in the tropics where the conditions are ideal for breeding. Malaria is an extremely climate sensitive tropical disease which makes it a grave concern because of global warming and climate change. A study from the East African highlands has confirmed biological response of mosquito populations to global warming. A half degree centigrade increase in temperature trend can translate into 30-100\% increase in mosquito abundance [1,2]. Malaria, which was once nearly eradicated, is re-emerging as the world's number one infection causing deaths. The disease now affects 300-500 million and kills 3 million people 
every year worldwide. About $90 \%$ of malaria cases occur in sub-Saharan Africa. The situation is compounded by high prevalence of HIV in the same region. Immune deficiency due to HIV infection makes humans more susceptible to malaria infection, also malaria fever has been noted to increase viral load by up to ten times [3]. Malaria is a major contributing factor to maternal morbidity and mortality because human immunity against the disease is reduced in pregnancy. Malaria infection during pregnancy results in severe illness with maternal complications such as severe anemia, thrombocytopenia, cerebral malaria, hemorrhage, renal failure and pulmonary edema. The disease is more severe and more fatal in pregnancy with $13 \%$ mortality against $6.5 \%$ in non-pregnant women [3].

According to World Health Organization (WHO), 30 million women living in malaria endemic areas become pregnant each year and $80 \%$ of deaths due to malaria occur in pregnancy and children under 5 years [101]. The disease has adverse effects on the fetus with increased risk of stillbirth, preterm delivery, intrauterine growth restriction and low birth weight which are leading causes of perinatal mortality. Congenital malaria, which is diagnosed by finding parasites in the neonate with no history of travel to an endemic area, has been found to have a prevalence varying from $8-33 \%$ in one study. [4].

Fifty percent of approximately 12 million people in Zimbabwe reside in areas that are endemic for malaria and the disease is responsible for $30 \%$ outpatient attendance. It is the third cause of mortality after HIV/AIDS and Tuberculosis in all age groups [102]. Key factors that influence general management and control of malaria are, drug resistance of the malaria parasite, safety and appropriate use of different anti-malarial drugs during pregnancy, high number of unbooked patients not monitored or followed up through antenatal facilities available, late presentation to hospital and delayed treatment of malaria cases, climate change which has influenced geographical distribution of malaria and finally role of HIV and transplacental transmission in patients with malaria in pregnancy.

\section{Patients And Methods}

A prospective cross-sectional descriptive study was conducted at Parirenyatwa Hospital (a tertiary centre in Harare) and three District Hospitals (Mudzi, Nyadire and Mutoko) in Mashonaland East Province of Zimbabwe over an 8-month period from September 2011 to April 2012. The district hospitals are in moderate to high seasonal malaria regions of Zimbabwe. Parirenyatwa Hospital is situated in a non-malaria zone and caters for cases that are referred from outside or those who develop the disease after traveling to malaria endemic areas. To the best of our knowledge this is the first such study to be conducted in Zimbabwe and probably the largest series of malaria in pregnancy in Zimbabwe. This study included consecutive pregnant women who presented and were admitted with malaria at the four study centres. About $13 \%$ of pregnant women who present with malaria develop severe complications. Based on this a sample size of about 174 was calculated for the study.

Data was collected from all pregnant women admitted to the antenatal, gynecology and labour ward with a diagnosis of malaria. An interviewer-administered questionnaire was used to collect data. The questionnaire consisted of structured questions, scaled questions and response questions on the participant's demographic data, antenatal care, malaria prevention and prophylaxis, maternal and fetal outcome. The data collected on each patient included demographic information, marital status, parity, booking status, HIV status, use of malaria prophylaxis, number of doses of IPT (intermittent preventive treatment) during pregnancy, duration of illness prior to hospitalization, method of diagnosis (clinical, slide positive or rapid malaria test), treatment method (oral or intravenous antimalarial drugs), duration of hospital stay and fetal and maternal outcomes. A pilot study was done at Parirenyatwa hospital to test the data collection form and necessary amendments were made. Data was entered into EXCEL. The data was cleaned and coded for analysis. All statistical analysis was performed using Stata 12.0 (Stata Cooperation, College Station, Texas USA). Permission was sought from the Joint Parirenyatwa Hospital and College of Health sciences Research Ethics Committee and Mashonaland East Provincial Medical Director. The purpose of the study was explained to all potential participants and a written informed consent was obtained.

\section{ReSUltS}

One hundred and three women who had malaria participated in the study. The burden of malaria requiring hospitalization as a proportion of total deliveries at each of the 4 institutions studied is illustrated in table 1. The patient characteristics are shown in table 2. Seventy-six participants (74\%) 
A Study of the Outcomes of 103 Pregnant Women Admitted with Malaria at Three District Hospitals in Mashonaland East Province and One Central Hospital in Harare Province in Zimbabwe

presented to hospital within three days (median=3 days, range-1-15days) of onset of symptoms. A smaller number 4(4\%), were admitted more than a week after onset of illness. Seven patients (7\%) out of 103 had previously been treated for malaria during the current pregnancy. Seventy-four (72\%) participants had signs and symptoms of severe malaria such as respiratory distress, prostration, hypotension, jaundice, coca cola colored urine, convulsions and abnormal bleeding.

Table1. The burden of malaria requiring hospital admission in the 4 institutions. (PGH= Parirenyatwa Hospital)

\begin{tabular}{|l|c|c|c|c|c|}
\hline & PGH & Nyadire & Mutoko & Kotwa & TOTAL \\
\hline Total Participants & 12 & 47 & 28 & 16 & 103 \\
\hline $\begin{array}{l}\text { Total Deliveries } \\
\text { during study }\end{array}$ & 6212 & 378 & 1386 & 668 & 8644 \\
\hline $\begin{array}{l}\text { Incidence per 1000 } \\
\text { deliveries }\end{array}$ & 2 & 124 & 19 & 24 & 12 \\
\hline
\end{tabular}

Table 2. Summary of patient characteristics

\begin{tabular}{|c|c|c|}
\hline \multicolumn{2}{|c|}{ Characteristic. } & \multirow{2}{*}{$\frac{\text { Number of women (\%) }}{13(13)}$} \\
\hline Hospital & Parirenyatwa Central & \\
\hline & Nyadire District & $47(45)$ \\
\hline & Mutoko District & $16(15)$ \\
\hline & Kotwa District & $27(27)$ \\
\hline \multirow[t]{4}{*}{ Marital Status } & Married & $96(93)$ \\
\hline & Single & $1(1)$ \\
\hline & Divorced & $5(5)$ \\
\hline & Widowed & $1(1)$ \\
\hline \multirow[t]{2}{*}{ Occupation } & Unemployed & $96(94)$ \\
\hline & Employed & $6(6)$ \\
\hline \multirow[t]{6}{*}{ Parity } & 0 & $31(30)$ \\
\hline & 1 & $26(25)$ \\
\hline & 2 & $19(19)$ \\
\hline & 3 & $17(16)$ \\
\hline & 4 & $7(7)$ \\
\hline & $\geq 5$ & $3(3)$ \\
\hline \multirow[t]{4}{*}{ Education Level } & None & $1(1)$ \\
\hline & Primary & $24(23)$ \\
\hline & Secondary & $76(74)$ \\
\hline & Tertiary & $2(2)$ \\
\hline \multirow[t]{4}{*}{ Religion } & Christian & $56(54)$ \\
\hline & Apostolic sect & $42(41)$ \\
\hline & Traditionalist & $3(3)$ \\
\hline & None & $2(2)$ \\
\hline \multirow[t]{2}{*}{ Residence } & Malaria area & $99(96)$ \\
\hline & Non-malaria area & $4(4)$ \\
\hline \multirow[t]{2}{*}{ Booking Status } & Booked & $65(63)$ \\
\hline & Not Booked & $38(37)$ \\
\hline \multirow[t]{4}{*}{ IPT Use } & None Used & $59(57)$ \\
\hline & 1 dose & $15(15)$ \\
\hline & 2 doses & $18(17)$ \\
\hline & 3 doses & $11(11)$ \\
\hline \multirow[t]{3}{*}{ Use of Bed Nets } & Always & $25(24)$ \\
\hline & Sometimes & $32(31)$ \\
\hline & Not at all & $46(45)$ \\
\hline \multirow[t]{3}{*}{ HIV Status } & Negative & $65(63)$ \\
\hline & Positive & $23(22)$ \\
\hline & Not Known & $15(15)$ \\
\hline
\end{tabular}


(a). Method of Diagnosis.

Rapid diagnostic test (RDT) and blood slides were the main diagnostic tools used at the four study centers. Patients who were suspected to have malaria clinically were confirmed by rapid diagnostic testing or blood slides. All participants had a positive result for one or both tests with $58 \%$ (60 patients) having slide positive malaria. Parasite density was recorded on 51(85\%) slides as described in Table 3.

Table 3. Parasite density on the 51 reported slides.

\begin{tabular}{|l|c|}
\hline Parasite Density & Proportion (\%) \\
\hline 1+, described as 1-10 asexual parasites per 100 thick film fields & 43 \\
\hline 2+, described as 11-100 asexual parasites /100 thick film fields & 39 \\
\hline 3+, described as 1-10 asexual parasites per single thick film field & 14 \\
\hline 4+, described as $>$ 10 asexual parasites per single thick film field & 4 \\
\hline
\end{tabular}

\section{(b). Haemoglobin and Platelets}

Only 37 patients had their haemoglobin $(\mathrm{Hb})$ checked of which $47.2 \%$ had $\mathrm{Hb}$ below $10 \mathrm{~g} / \mathrm{dl}$. About $16.6 \%$ of patients had haemoglobin below $7 \mathrm{~g} / \mathrm{dl}$, which is one of the Centre for Disease Control (CDC) criteria for complicated malaria. A thrombocytopenia below $100 \times 10^{9} / \mathrm{L}$ was seen in $30 \%$ of patients.

\section{(c). Use of intermittent preventive treatments (IPT) and insecticide treated bed nets (ITN) as prevention methods}

The commonly used prevention methods in Zimbabwe are intermittent preventive treatment (IPT)according to WHO guidelines, bed nets, insecticide repellants and protective clothing to minimize nocturnal exposure to mosquito bites. The recommended regimen for IPT in Zimbabwe consists of Fansidar (Pyrimethamine 25mg/Sulfadoxine 500mg combination) 3 tablets at once after confirming fetal movements and then repeated at 28 and 36 weeks gestation. Intermittent preventive treatment (IPT) was the most commonly used prevention method with 44(42\%) participants receiving at least one dose of Fansidar but only $11 \%$ receiving the full 3 doses (Figure 1). However a significant proportion of participants $(45 \%)$ who were at risk did not receive IPT. Of these patients $55 \%$ were not registered for antenatal care.

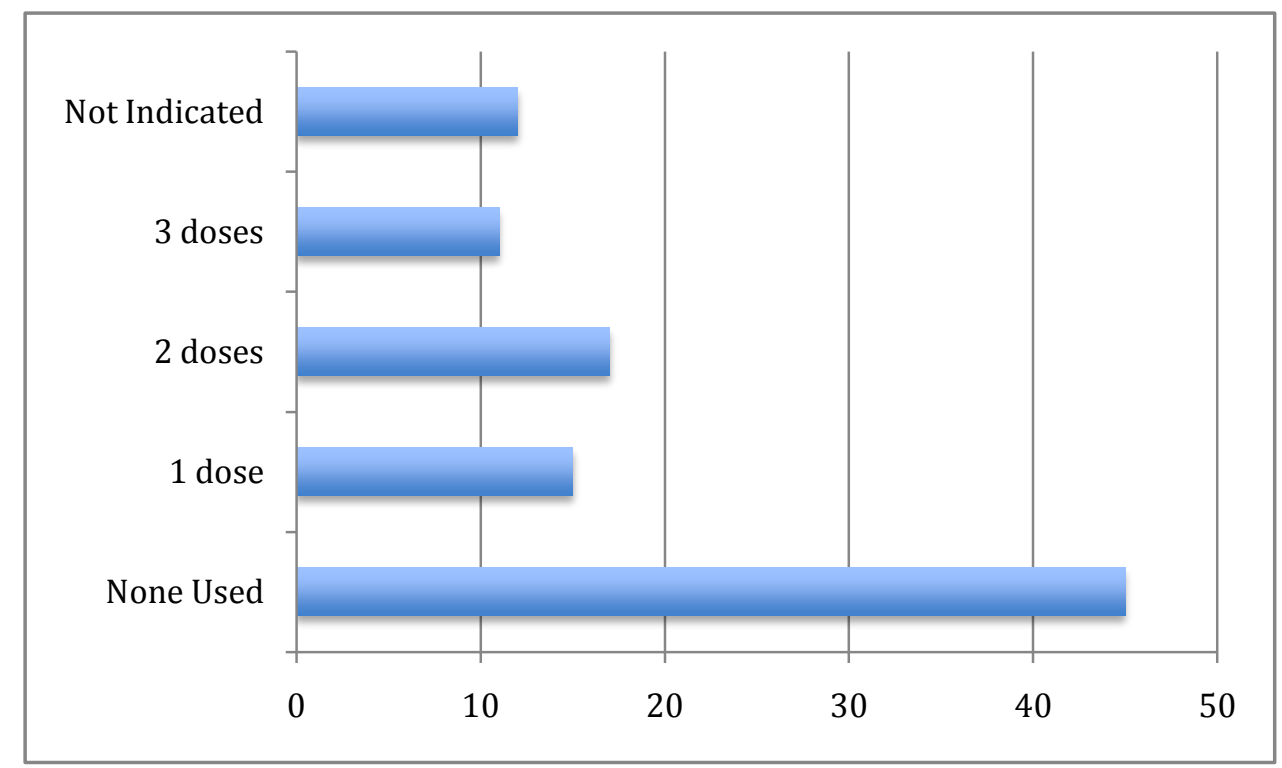

Figure 1. percentage use of intermittent preventive treatment (Pyrimethamine $25 \mathrm{mg} /$ Sulfadoxine $500 \mathrm{mg}$ ).

A large proportion of participants $46(45 \%)$ never used insecticide treated bed nets and 32(31\%) were using them but not all the time. Only $24 \%$ were using bed nets consistently.

\section{(d). Treatment Methods}

The treatment regimens used in the 103 patients are illustrated in Figure 2, which demonstrates that the majority (78\%) of participants were treated with quinine orally or intravenously or both. Forty- 
A Study of the Outcomes of 103 Pregnant Women Admitted with Malaria at Three District Hospitals in Mashonaland East Province and One Central Hospital in Harare Province in Zimbabwe

three (42\%) of the participants were treated with intravenous quinine (1-4days) and course completed with oral quinine and $37(36 \%)$ were given oral quinine only. The results suggest that Chloroquine to which significant resistance has been reported is no longer used widely in Zimbabwe.

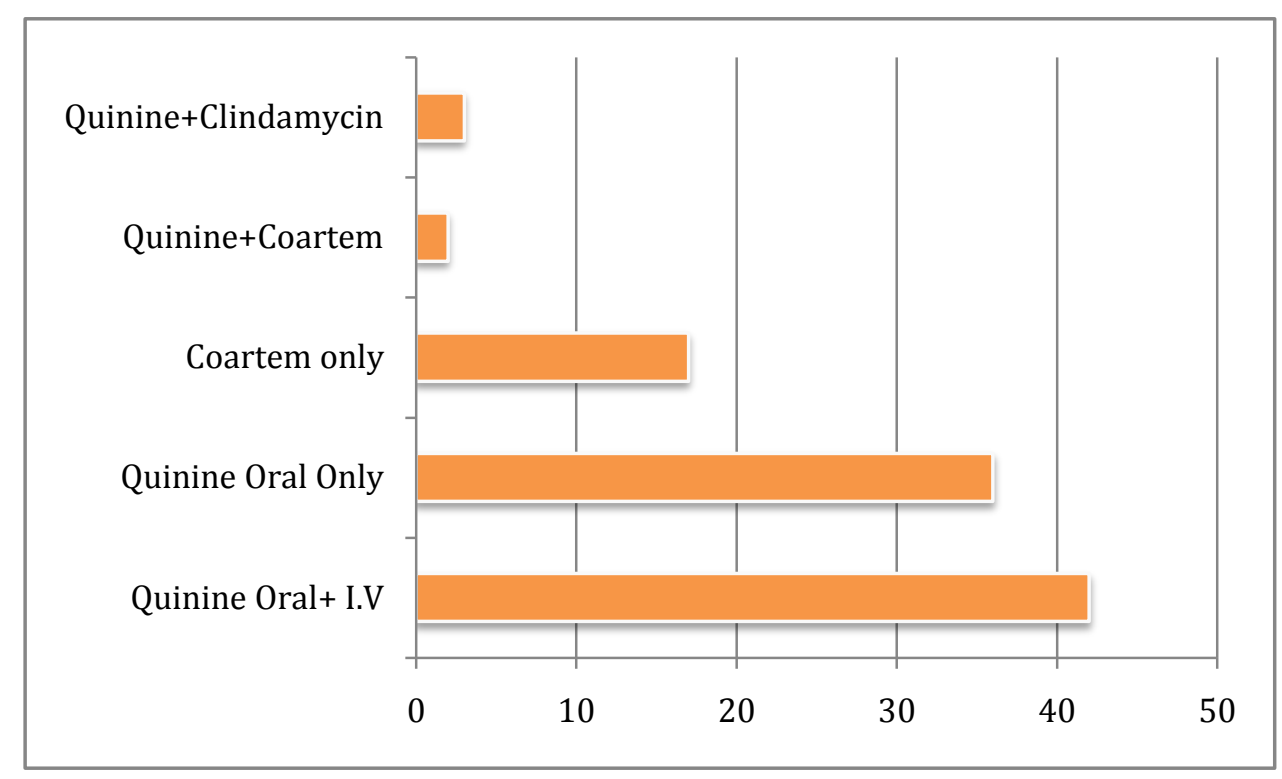

Figure 2. malaria treatment regimens and drugs used in pregnancy (\%).

\section{(e). Maternal outcomes in relation to antenatal parameters (Table 4).}

The majority (92\%) of patients were treated successfully and discharged from hospital without experiencing severe complications. The 2 cerebral malaria and 2 maternal deaths did not receive intermittent preventive treatment while of the 6 with severe anaemia, only 2 did not receive IPT.

Table 4. Maternal outcomes and their antenatal parameters

\begin{tabular}{|c|c|c|c|c|}
\hline Parameter & $\begin{array}{l}\text { Discharge without } \\
\text { major } \\
\text { complications }(n=93) \\
\text { n(\%) }\end{array}$ & $\begin{array}{l}\text { Maternal } \\
\text { death }(n=2) \\
n(\%)\end{array}$ & $\begin{array}{l}\text { Severe anaemia } \\
(n=6) n(\%)\end{array}$ & $\begin{array}{l}\text { Cerebral malaria } \\
(\mathrm{n}=2) \mathbf{n}(\%)\end{array}$ \\
\hline \multicolumn{5}{|l|}{ Booking status } \\
\hline Booked & $61(66)$ & $1(50)$ & $2(33)$ & $1(50)$ \\
\hline Un-booked & $32(34)$ & $1(50)$ & $4(67)$ & $1(50)$ \\
\hline \multicolumn{5}{|l|}{ IPT use } \\
\hline None & $43(46)$ & $2(100)$ & $2(33)$ & $2(100)$ \\
\hline 1 dose & $15(16)$ & $0(0)$ & $0(0)$ & $0(0)$ \\
\hline 2 doses & 18(19) & $0(0)$ & $0(0)$ & $0(0)$ \\
\hline 3 doses & 11(12) & $0(0)$ & $0(0)$ & $0(0)$ \\
\hline Not indicated & $6(7)$ & $0(0)$ & $4(66.7)$ & $0(0)$ \\
\hline \multicolumn{5}{|l|}{ Bed net use } \\
\hline Always & $24(26)$ & $0(0)$ & $0(0)$ & $0(0)$ \\
\hline Sometimes & $30(32)$ & $0(0)$ & $0(0)$ & $1(50)$ \\
\hline Not at all & $38(41)$ & $2(100)$ & $6(100)$ & $1(50)$ \\
\hline \multicolumn{5}{|l|}{$\begin{array}{l}\text { Previous } \\
\text { treatment }\end{array}$} \\
\hline No & $83(89)$ & $2(100)$ & $6(100)$ & $2(100)$ \\
\hline Yes & $10(11)$ & $0(0)$ & $0(0)$ & $0(0)$ \\
\hline \multicolumn{5}{|c|}{$\begin{array}{l}\text { Duration of illness } \\
\text { prior to admission }\end{array}$} \\
\hline $1-3$ & $73(79)$ & $0(0)$ & $2(33)$ & $0(0)$ \\
\hline $3-7$ & $17(18)$ & $0(0)$ & $4(67)$ & $1(50)$ \\
\hline$>7$ & $3(3)$ & $2(100)$ & $0(00)$ & $1(50)$ \\
\hline
\end{tabular}


Dr Muchabayiwa F Gidiri et al.

\begin{tabular}{lllll}
\hline \hline Trimester & & & & \\
$\mathbf{1}$ & $5(5)$ & $0(0)$ & $2(33)$ & $0(0)$ \\
$\mathbf{2}$ & $21(23)$ & $1(50)$ & $2(33)$ & $0(0)$ \\
$\mathbf{3}$ & $67(72)$ & $1(50)$ & $2(33)$ & $2(100)$ \\
& & & & \\
Parasite density & & & & $0(0)$ \\
$1+$ & $22(24)$ & $0(0)$ & $1(17)$ & $2(100)$ \\
$2+$ & $17(18)$ & $0(0)$ & $2(33)$ & $0(0)$ \\
$3+$ & $6(7)$ & $0(0)$ & $3(50)$ & $0(0)$ \\
$4+$ & $0(0)$ & $1(50)$ & $0(00)$ & $0(0)$ \\
Not recorded & $42(45)$ & $1(50)$ & $0(00)$ & $1(50)$ \\
HIV Status & & & & $1(50)$ \\
Negative & $61(66)$ & $0(0)$ & $3(50)$ & $0(0)$ \\
Positive & $17(18)$ & $1(50)$ & $3(50)$ & $0(0)$ \\
Not known & $15(16)$ & $1(50)$ & & \\
\hline
\end{tabular}

(f). Fetal and neonatal outcomes in relation to antenatal parameters.

Figure 3 illustrates birth weights for all patients who had delivered by the time of hospital discharge and $30 \%$ babies had low birth weight $(<2500 \mathrm{~g})$.

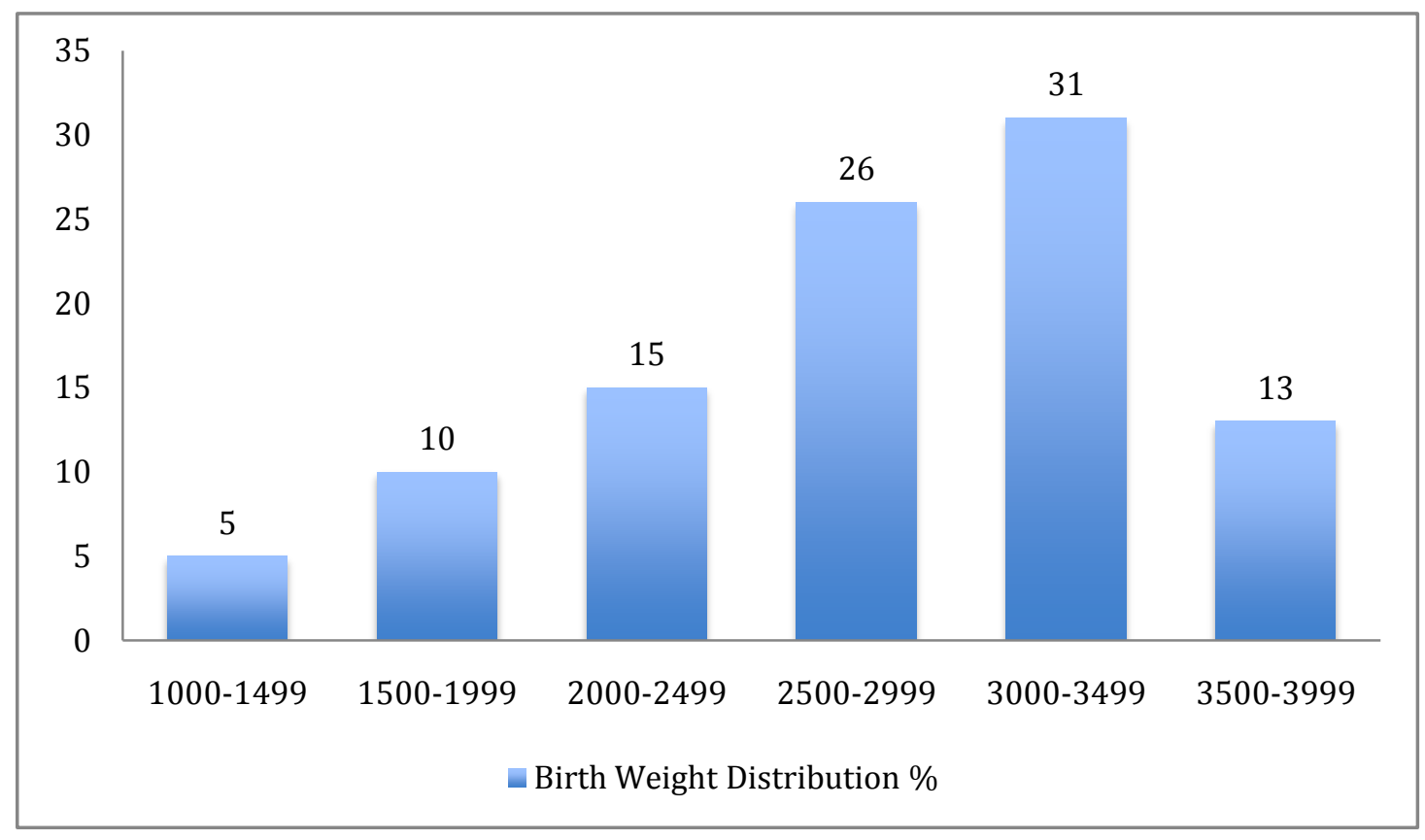

Figure 3. Birth weight distribution of babies delivered to mothers treated for malaria in pregnancy (\%).

Fifty-two participants (52\%) had not delivered by the time of discharge from hospital. Of the 51(48\%) who had delivered at the time of discharge $6(6 \%)$ had stillbirth, $10(10 \%)$ preterm delivery, $9(9 \%)$ miscarriages and 24(23\%) had live term babies (Table 5).

Table 5. Fetal outcome and maternal antenatal parameters

\begin{tabular}{|c|c|c|c|c|c|c|}
\hline Characteristic & $\begin{array}{l}\text { Normal } \\
\text { term baby } \\
(n=24) n / \%\end{array}$ & $\begin{array}{l}\text { Preterm } \\
\text { delivery } \\
(\mathbf{n}=10) \\
\mathbf{n} / \%\end{array}$ & $\begin{array}{l}\text { Low birth } \\
\text { weight } \\
(\mathrm{n}=12) \\
\mathbf{n} / \%\end{array}$ & $\begin{array}{l}\text { Stillbirths } \\
(\mathbf{n}=6) \\
\mathbf{n} / \%\end{array}$ & $\begin{array}{l}\text { Miscarriage } \\
(\mathbf{n}=9) \\
n / \%\end{array}$ & $\begin{array}{l}\text { Threatened } \\
\text { miscarriage } \\
(\mathrm{n}=2) \\
\mathrm{n} / \%\end{array}$ \\
\hline \multicolumn{7}{|l|}{ Booking status } \\
\hline Booked & 19(79) & $6(60)$ & $6(50)$ & $4(67)$ & $2(22)$ & $0(0)$ \\
\hline Un-booked & $5(21)$ & $4(40)$ & $6(50)$ & $2(33)$ & $7(78)$ & $2(100)$ \\
\hline \multicolumn{7}{|l|}{ IPT use } \\
\hline Non & $9(38)$ & $4(40)$ & $7(58)$ & $4(67)$ & $4(44)$ & $2(100)$ \\
\hline 1 dose & $3(12)$ & $1(10)$ & $0(0)$ & $1(17)$ & $0(0)$ & $0(0)$ \\
\hline 2 doses & $4(17)$ & $3(30)$ & $3(25)$ & $1(17)$ & $0(0)$ & $0(0)$ \\
\hline 3 doses & $8(33)$ & $2(20)$ & $0(0)$ & $0(0)$ & $1(12)$ & $0(0)$ \\
\hline Not indicatec & & & & & & \\
\hline
\end{tabular}


A Study of the Outcomes of 103 Pregnant Women Admitted with Malaria at Three District Hospitals in Mashonaland East Province and One Central Hospital in Harare Province in Zimbabwe

\begin{tabular}{|c|c|c|c|c|c|c|}
\hline & $0(0)$ & $0(0)$ & $2(17)$ & $0(0)$ & $4(44)$ & $0(0)$ \\
\hline \multicolumn{7}{|l|}{ Bed net use } \\
\hline Always & $2(8)$ & $3(30)$ & $2(17)$ & $1(17)$ & $1(11)$ & $0(0)$ \\
\hline Sometimes & $8(33)$ & $4(40)$ & $4(33)$ & $3(50)$ & $1(11)$ & $2(100)$ \\
\hline Not at all & $15(63)$ & $3(30)$ & $6(50)$ & $2(33)$ & $7(78)$ & $0(0)$ \\
\hline \multicolumn{7}{|c|}{ Parasite dansity } \\
\hline $2+$ & $4(17)$ & $2(20)$ & $2(17)$ & $2(33)$ & $2(22)$ & $0(0)$ \\
\hline $3+$ & $6(24)$ & $4(40)$ & $4(33)$ & $0(0)$ & $2(22)$ & $0(0)$ \\
\hline $4+$ & $3(13)$ & $0(0)$ & $0(0)$ & $1(17)$ & $0(0)$ & $0(0)$ \\
\hline \multirow{2}{*}{ Not recorded } & $0(0)$ & $0(0)$ & $0(00$ & $1(17)$ & $0(0)$ & $1(50)$ \\
\hline & 11(46) & $4(40)$ & $6(50)$ & $2(33)$ & $5(56)$ & $1(50)$ \\
\hline \multicolumn{7}{|l|}{ HIV Status } \\
\hline Negative & $15(63)$ & $4(40)$ & $4(33)$ & $2(33)$ & $4(44)$ & $1(50)$ \\
\hline Positive & $7(29)$ & $6(60)$ & $7(58)$ & $3(50)$ & $2(22)$ & $1(50)$ \\
\hline Not known & $2(8)$ & $0(0)$ & $1(9)$ & $1(17)$ & $3(34)$ & $0(0)$ \\
\hline \multicolumn{7}{|c|}{ HIV treatment } \\
\hline HAART & $1(4)$ & $2(20)$ & $2(17)$ & $0(0)$ & $0(0)$ & $1(50)$ \\
\hline $\mathrm{AZT}$ & $5(21)$ & $0(0)$ & $3(25)$ & $3(50)$ & $0(0)$ & $0(0)$ \\
\hline None & $1(4)$ & $4(40)$ & $4(33)$ & $3(50)$ & $2(22)$ & $0(0)$ \\
\hline $\begin{array}{l}\text { Negative/Stat } \\
\text { not known }\end{array}$ & $17(71)$ & $4(40)$ & $3(25)$ & $0(0)$ & $7(78)$ & $1(50)$ \\
\hline
\end{tabular}

\section{DISCUSSION}

Total deliveries at the four study institutions during the period of study were 8644 .

There were 103 consecutive pregnant women diagnosed with malaria during the study period. The majority of the women were housewives and households thrived on peasant farming which is common to rural populations in Zimbabwe. This could have a bearing on the capacity of the women to access healthcare services such as antenatal care as indicated by a high proportion (37\%) of the participants who were not booked for antenatal care compared to the national figure of $8.6 \%$ [5].

The majority (96\%) of the participants were resident in malaria prone regions of Zimbabwe. Only $4 \%$ were resident in malaria free regions. They developed malaria after travelling to regions with malaria and none of them had taken prophylaxis for malaria during travel. The results demonstrated that Harare, the capital city of Zimbabwe, which is the main catchment area for Parirenyatwa Hospital largely, remained malaria free as has always been known. All 13 participants who were admitted at this hospital had malaria after travelling to places outside Harare or were referred from outside Harare with diagnosis of malaria.

Primigravida women formed a large group among the study population 31(30\%). This was consistent with studies, which have shown that primigravida women are more susceptible to malaria $[\mathbf{6 , 7 , 8 ]}$.

A significant proportion of participants booked late, 19(29\%) booking in the third trimester. The proportion that was not booked together with those that booked late was high 57(55\%). This compromised provision of antenatal care services and implementation of preventive measures to pregnant women at risk of malaria infection such as IPT. The participants who were not booked could not be given IPT and those who booked late missed some doses. Studies have shown evidence of significant benefit of IPT in reduction of malaria infection in pregnancy and associated complications $[\mathbf{9 , 1 0}]$.

Seventy-three $(70 \%)$ participants developed malaria in the third trimester. These could have been prevented from developing malaria if they had booked early and preventive measures were implemented strictly.

The proportion of participants who had HIV infection 23(22\%) was high compared to $16 . \%$ for women attending antenatal clinics countrywide according to the Zimbabwe Ministry of Health \& 
Child Welfare's (MOHCW) PMTCT data base. This was consistent with studies that showed increased susceptibility of HIV positive pregnant women to malaria compared to HIV negative [11, 12].

Current recommendations to prevent malaria in African pregnant women rely on insecticide treated nets (ITNs) and intermittent preventive treatment (IPT). In a randomized control trial done in Mozambique (9), Sulfadoxine Pyrimethamine (SP) showed 40\% reduction in the incidence of clinical malaria during pregnancy, and reductions in the prevalence of peripheral parasitaemia $(7.10 \%$ vs. $15.15 \%)(\mathrm{p}<0.001)$, and of actively infected placentas $(7.04 \%$ vs. $13.60 \%)$. However in this study, $44.6 \%$ of the participants developed malaria despite receiving at least one dose of IPT. This gives rise to questions on whether IPT with SP is still effective in our environment or the malaria parasite has developed resistance to it. Non-use of IPT was $44.7 \%$ and this was largely because $54.3 \%$ of them were not registered for ANC.

A Malawian study demonstrated underutilization of ITNs (insecticide treated bed nets) by participants, which plays a complimentary role to ITP in prevention of malaria infection [10]. In our study $45 \%$ of the participants never used ITNs during the course of their pregnancy up to the time they were admitted with malaria.

Rapid diagnostic test (RDT) was the main diagnostic tool used by the four study centers. There were limitations in the use of blood slide (gold standard), which was done in 58\% of the participants. This was because of shortage of skilled manpower and unavailability of reagents. Diagnosis using blood slides has advantages over RDT because parasite density can be estimated and the malaria species can be identified.

The same reason was responsible for unavailability of other laboratory investigations such as full blood count and urea and electrolytes that were done on a small proportion of participants $35.5 \%$, and $12.6 \%$ respectively. The unavailability of such laboratory tests especially in rural hospitals made it difficult to assess participants for other complications like renal failure.

Most of the participants were treated according to standard guidelines; however some patients who had severe anaemia did not receive transfusion because of non-availability of blood and related blood products.

Ninety-five (92\%) participants were discharged from hospital without major complications and 52\% were still pregnant. This is important as it suggests that the malaria in those regions is still responsive to the commonly used and available drugs in Zimbabwe. Among the maternal adverse outcomes observed were 2 maternal deaths, 4 participants with severe anaemia and 2 with cerebral malaria. The majority $(65 \%)$ of participants who were registered for antenatal care were discharged without complications. More complications were observed in those not booked. Booking status of participants therefore could have an effect on maternal outcome.

None use of IPT was associated with adverse outcome. All participants who deceased and those who had cerebral malaria did not use IPT. The number of IPT doses taken was inversely proportional to the number of participants who were discharged without severe complications.

Participants who deceased did not use IPT and ITNs and presented to hospital more than a week after onset of illness. None use of ITNs was also associated with severe anaemia. None of the participants who had severe anaemia had used ITNs. Of those who were discharged without complications, $41 \%$ did not use ITNs at all compared to $26 \%$ who consistently used ITNs.

Fetal loss due to miscarriage $9(\%)$ and stillbirths $6(6 \%)$ was high. There were also a high proportion of preterm deliveries and low birth weight babies. Adverse fetal outcomes were high in participants who did not use IPT, ITNs, and HIV positive not on HAART or PMTCT prophylaxis.

\section{CONClusion}

Malaria is a significant cause of maternal morbidity in Zimbabwe. In pregnancy malaria parasites tend to be sequestered in the placenta, which may make it difficult to eradicate it if treatment and follow-up are sub-optimal.

Malaria infection has adverse effects on both mother and fetus. It was associated with maternal mortality $(2 \%)$. Anaemia, cerebral malaria, and maternal death were the main maternal complications 
encountered in this study. Maternal adverse outcome was influenced by booking status, HIV status, use of IPT, ITNS and late presentation to hospital. There was high fetal loss (15\%) resulting from miscarriages $(9 \%)$ and stillbirths $(6 \%)$. Malaria infection was also associated with low birth weight $(30 \%)$ and preterm delivery $(10 \%)$.

The study also revealed that there was underutilization of prevention strategies (IPT and ITNs) by $45 \%$ of participants, which was mainly due to failure to book for ANC or late booking. Case management was generally according to standard guidelines but participants were not adequately investigated in terms of other parameters such as blood count and renal function. This was mainly due to limited availability of laboratory services and skilled manpower.

Future programs on malaria in pregnancy will need to emphasize on provision of health education through accessible media to populations in malaria endemic regions emphasizing need for early booking of pregnancies for antenatal care and use of preventive measures during pregnancy. Further research is required to evaluate Pyrimethamine/Sulfadoxine as the drug of choice for IPT and the assessment of its efficacy and the feasibility of using a combination of drugs for IPT. Future studies would be required to assess the feasibility of using intermittent- screening and treatment methods which involves screening patients at antenatal visits and treating those who test positive especially in malaria-prone areas. Future work should also focus on assessment of barriers that lead to low uptake of currently available preventive measures by populations in malaria regions. Countries with high seasonal malaria infection should ensure provision of adequate laboratory facilities for rapid diagnosis and skilled manpower to assess severity of malaria especially for rural hospitals.

\section{REFERENCES}

[1] Caminade $\mathrm{C}$, Kovats $\mathrm{C}$, Rocklov $\mathrm{J}$ et al. Impact of climate change on global malaria distribution. Proc Natl Acad Sci 2014; 111(9): 3286-3291.

[2] Pascual M, Ahumada JA, Chaves LF, Rodo X, Bouma M. Malaria resurgence in the East African highlands: temperature trends revisited. Proc Natl Acad Sci 2006; 103(15): 5829-5834.

[3] Abu-Raddad LJ, Patnaik P, Kublin JG. Dual infection with HIV and malaria fuels the spread of both diseases in sub-Saharan Africa. Science 2006;314(5805): 1603-1606.

[4] Desai M, ter Kuile FO, Nosten F, McGready R, Asamoa K, Brabin B, et al. Epidemiology and burden of malaria in pregnancy. Lancet Infect Dis 2007; 7: 93-104.

[5] Ministry of Health and Child Welfare Zimbabwe. Maternal and Perinatal Mortality Study. (2007)

[6] McGregor IA. Thoughts on malaria in pregnancy with consideration of some factors, which influence remedial strategies. Parassitologia 1987;29: 153-63.

[7] Brabin BJ, Ginny M, Brabin L, Eggelte T, Van der Kaay HJ. Failure of Chloroquine prophylaxis for falciparum malaria in pregnant women in Madang, Papua New Guinea. Ann Trop Med Parasitol 1990; 84(1): 1-9.

[8] 8. Brabin BJ, Agbaje SOF, Ahmed Y, Briggs ND. A birthweight normogram for Africa, as a malaria control indicator. Ann Trop Med Parasitol 1999; 93(1): 43-57.

[9] Menendez C, Bardaji A, Sigauque B et al. A randomized placebo-controlled trial of intermittent preventive treatment in pregnant women in the context of insecticide treated nets delivered through the antenatal clinic. PLoS One 2008; 3(4): e1934.

[10] Feng G, Simpson JA, Chaluluka E, Molyneux ME, Rogerson SJ. Decreasing burden of malaria in pregnancy in Malawian women and its relationship to use of intermittent preventive therapy or bed nets. PLoS One 2010; 5(8): e12012.

[11] Wumba RD, Zanga J, Aloni MN et al. Interactions between malaria and HIV infections in pregnant women: a first report of the magnitude, clinical and laboratory features and predictive factors in Kinshasa, the Democratic Republic of Congo. Malar J 2015; 14(82): 1-11.

[12] Ticconi C, Mapfumo M, Dorrucci M, Naha N, Tarira E, Pietropolli A, Rezza G. Effect of maternal HIV and malaria infection on pregnancy and perinatal outcome in Zimbabwe. J Acquir Immune Defic Syndr 2003; 34(3): 289-94. 


\section{WEBSITES}

[1] World Health Organization. Lives at risk: malaria in Pregnancy. $4^{\text {th }}$ Bulletin. Geneva. 2003. [www.who.int/features/2003/04bn/en/].

[2] Zimbabwe Ministry of Health and Child Welfare, National Malaria Control Programme. Malaria Control Programme review report. (2011). [http://www.rollbackmalaria.org/files/files/countries/ Zimbabwe-The-malaria-program-performance-review-2011-Report.pdf] 